American Journal of Remote Sensing
2020; 8(2): $50-57$
http://www.sciencepublishinggroup.com/j/ajrs
doi: 10.11648 /j.ajrs.20200802.12
ISSN: 2328 -5788 (Print); ISSN: 2328 -580X (Online)

\title{
Experiments and Analysis Advance R2100 Distance Sensors Used for Safety Systems of TOMI
}

\author{
Chunhua Zhao", *, Simon Blackmore ${ }^{2,3}$, *, Sam Wane ${ }^{2}$, Michael Warbrick² \\ ${ }^{1}$ Mechanical and Electronic Engineering College, Gansu Agricultural University, Lanzhou, China \\ ${ }^{2}$ Engineering College, Harper Adams University, Newport, UK \\ ${ }^{3}$ National Precision Agriculture Engineering Innovative Centre, Newport, UK
}

\section{Email address:}

zhaochunhau20121012@foxmail.com (Chunhua Zhao), simon.blackmore@harper-adams.ac.uk (S. Blackmore), mwarbrick@harper-adams.ac.uk (M. Warbrick), swane@harper-adams.ac.uk (S. Wane)

${ }^{*}$ Corresponding author

\section{To cite this article:}

Chunhua Zhao, Simon Blackmore, Sam Wane, Michael Warbrick. Experiments and Analysis Advance R2100 Distance Sensors Used for Safety Systems of TOMI. American Journal of Remote Sensing. Vol. 8, No. 2, 2020, pp. 50-57. doi: 10.11648/j.ajrs.20200802.12

Received: October 12, 2020; Accepted: October 27, 2020; Published: November 4, 2020

\begin{abstract}
In order to increase safety systems reliability of TOMI harvester, it is necessary to use advance R2100 Distance sensors which can scan all kinds of targets and receive data from automatic control system. The Structure and function of R2100 Distance sensors were provided in this paper, In order to determine the best application function of the R2100, effectiveness of R2100 sensors used for TOMI robot with robotic cutting forage were tested and analyzed. For application in precision agricultural engineering automatic control safety systems, static tests were applied with a box, cylinder, cone and person as 4 target samples which were set at different points and lines with each segment at $8^{\circ}$ angle within 11 segments, the target samples were set at $0^{\circ}, 14^{\circ}, 44^{\circ}, 74^{\circ}$ and $88^{\circ}$ angles with the reference of the sensor at centre, respectively, samples represent obstacles such as tractors, telegraph pole, car, and person which were detected and received by TOMI equipped with R2100 Distance sensors. TOMI Robot equipped with R2100 sensors setting at 240, 420 and $850 \mathrm{~mm}$ height, respectively, were set location at about $0.2 \mathrm{~m}, 0.3 \mathrm{~m}, 0.5 \mathrm{~m}, 1 \mathrm{~m}, 1.5 \mathrm{~m}, 2 \mathrm{~m}, 2.5 \mathrm{~m}, 3 \mathrm{~m}, 3.5 \mathrm{~m}$ and then added up to $0.5 \mathrm{~m}$ step up to $10 \mathrm{~m}$ with the reference of $\mathrm{R} 2100$ sensor in semicircle centre, respectively. In dynamistic testing, the target samples were set at the same method and location, and TOMI robot equipped with Advance R2100 sensors was running at speed of $0.8 \sim 1.2 \mathrm{~m} / \mathrm{s}$ from $5 \mathrm{~m}$ to the test centre in dynamistic tests. Tests and statistical evaluate results showed that the average $\mathrm{R}^{2}$ on TOMI robot was up to $98.96 \%$ in static tests, while the average $\mathrm{R}^{2}$ is up to $98.67 \%$ in dynamistic test, and as far as TOMI robot's safety system, $420 \mathrm{~mm}$ height was the best location for scanning all kinds of obstacles. The experiment results showed that the Advance R2100 was accurate sensor for application, it had been carried out on TOMI's intelligence safety systems which more practical and safety working in various fields.
\end{abstract}

Keywords: Distance Sensor, Safety, Structure and Function, Data, Tests and Analysis

\section{Introduction}

It is well known that all sensors have advantages and disadvantages, two main factors should be considered before choosing Advance sensors: Reliability and economical Application function. Consider economical practical function as intelligent harvester named as TOMI using for cutting forage [1], knowledge of certain sensors can help users avoid obstacles [2], Development the safety systems of robot were used for harvester, which considered ensuring a successful sensing application [3-4], simplicities of mounting and setup
[5] Advance applications of R2100 sensors were showed that sending frame position detection: injection mold closure detection [7]; Lathe's automatic control such as float detection for flow control [8-9].

\section{Structure and Function}

OMD8000-R2100-R2-2V15 type of R2100 Distance sensors was used to test accurate with $3 \mathrm{D}$ direction scanning range of $88^{\circ}$ and multi-beam LCD scanner using test Pulse Ranging and 3D valid max-distance, Structure and function were showed about pulse ranging technology (PRT) and 
following application tests which boasting a wide field of coverage with from 0.2 to $2 \mathrm{~m}$ at bw $6 \%$ and from 0.2 to $8 \mathrm{~m}$ at wb $90 \%$ [10]. The eyes protection LCD technology in the sensor allows using in various working areas without posing danger. The 11 emitter elements were arranged side by side span scanning range of $88^{\circ}$ as showing in Figure 1, while the emitter LCD isolates themselves by their large spots. Measuring the surface rather than a point makes it easier to measure on homogeneous surfaces. The absence of any parts or device, such as bearings or motor, makes the intelligence TOMI with 2 outputs A, B (respectively $3.3 \mathrm{~V}$ and $5 \mathrm{~V}$ with $\max 250 \mathrm{~mA})$ and one input $\mathrm{C}(5 \mathrm{~V}$ with $\max .100 \mathrm{~mA})$ checking more complex, the restarting input can be allocated as restart or for changing fields. The power was supplied to the device using a plug-in connection box with a high enclosure rating, and the interface connection was made through another connection box (RS232). Effective pulse ranging technology (PRT) ensures reliable and stable 2D measurement results independent of the application environment. These made Advance R2100 sensors truly unique solution for a wide range of safety harvesting tasks [11].
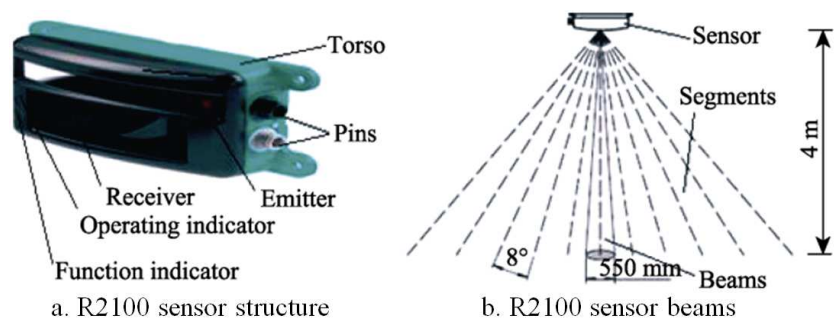

Figure 1. R2100 sensor structure and beam geometry.

The Advance R2100 Distance sensor using in the safety systems of TOMI may be described as "detecting R2100 Distance" from the center emitter to the position at which the proximity sensor operates when measured from the reference position with the standard detectable target. R2100 Distance sensor Scanning targets may not able to receive the manufacture's data [12]. These targets may be independently tested and measured, and the accurate of detecting Advance R2100 Distance may be effected by others sensors which couple with using in precision agricultural engineering [13].

\section{Materials and Methods}

In order to increase the reliability in new safety systems of TOMI and ensure the safety systems are correct running with 2 multifunction control systems and safety control systems for TOMI, the Advance R2100 Distance sensors were connected RS232 with TOMI's safety control system, it can send and request the obstacle's information, and received the echoes data, then, the information of R2100 Distances or echoes would be responded and received the information within $3 \mathrm{~s}$, the central electronics boards in safety control systems of TOMI were built, as showing in Figure 2.

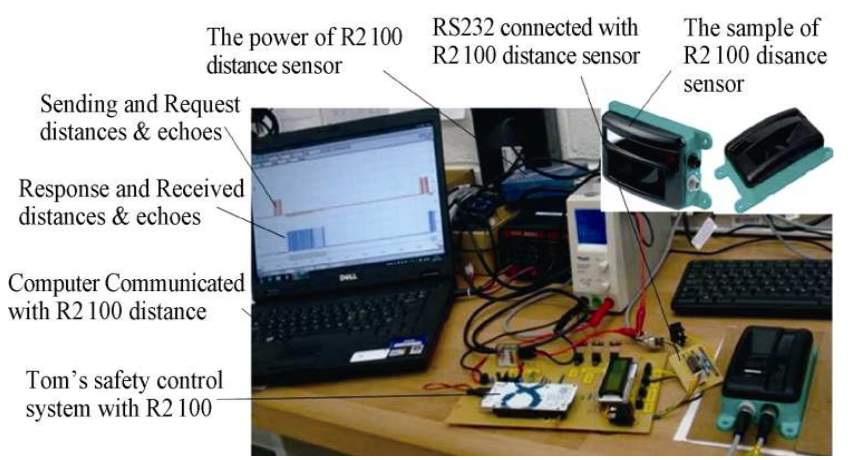

Figure 2. Static testing R2100 sensor using in TOMI's safety system with intelligence safety control systems.

\subsection{Data Logger of Tests}

Advance R2100 sensors such as OMD8000-R2100-R2-2V15 type of R2100 produced by Pepperl+Fuchs AG Ltd were used Figure 1 and 2 configurations for the serial ports [14].

\subsubsection{Theory and Technical data of R2100 Distance Sensor}

The baud rate of serial port is set to $19200 \mathrm{bps}$, using 8 bits and 1 stop bits, the resolution of R2100 sensor is up to $1 \mathrm{~mm}$ and, R2100 interface connection takes place through RS 232 with Intel Galileo, To evaluate the R2100 sensors, pulse ranging technology (PRT) and array of wide-beam LCD emitters are used as the measuring method in 2D with multi-beam scan-evaluating $2 \mathrm{D}$ area. Combining this technology with PRT is ensure to reliable detection of any surface, regardless of shape or size, R2100 can delivers extra durability, ruggedness, and measurement stability of R2100 Distances equipped with TOMI Robot.

Microprocessor which the type of Philips P87LPC762BN was produced by Philips, The Netherlands with functions of timer was used in static tests, once a pulse on the vibration sensor was detected, the microprocessor, switches of the circuit on for a pre-established time in via a constable stage were used in dynamistic tests. The FSK (frequency shift keying) modulation technique allows greater protection against electric noise compared to other types of RF modulations.

\subsubsection{Communicating and Echoes to R2100 Sensor}

Arduino and easy radio with functions of store program and transmission can receive data for serial interface board, it provides an easy to use, convenient communications to adapt or for shifting between RS232 serial protocol and TTL logic levels in dynamitic tests. The RF transmission module is a device based on TTL-RS232 logic (bit rate ranges from 9600 to $115200 \mathrm{bps}$ ), and data transmission is realized by the "store and forward" technique: input data are stored in a buffer memory and transmitted at the end of reception. In the reception phase, the bytes are stored and transferred to the serial port only after the check sum validation. In case of transmission failure, all received bytes are rejected (in other words, the radio message must be completely transmitted). The communication between the sensor and targets are based on frame messages using 4 
bytes such as sender ID information and receiver accurate distance data, length of the complete frame and command has to be sent to the R2100, then, the R2100 sensor answers and responds R2100 Distances \& echoes. By sending “AT" type commands of the communication channel, serial speeds, output transmission interval, power transmission and the identifying code can be selected by the user. To this end, for every triggering cycle, the same transmitter can be configured by using appropriate software. When the transmitter is powered, the transmission module receives the code which generated by microprocessor, then the code passes through the FSK modulator device, the high frequency created is amplified and filtered by a band-pass filter to eliminate all harmonic waves. Finally, the signal can be transmitted witlessly.

Code generator, the microprocessor is generated through time programmable radio frequency serial hex code which made up of 49 bytes numerical characters. This preset universal code for each specific implement is generated by micro process or triggered by the vibration sensor at a pre-defined frequency (commonly 1 code every $30 \mathrm{~s}$ ). Scanning rate is $50 \mathrm{~s}^{-1}$ ( 1 scan is equal to 11 segments of a beam measurements).

\subsection{Sending and Request About R2100 Sensor}

R2100 Distance sensor send and request the frame which has 5 bytes: $0 \times$ de, $0 \times 01,0 \times 05,0 \times 59$ and $0 \times 83$ from byte 0 to byte 4 respectively, this request should not be sent more often than every $20 \mathrm{~m} / \mathrm{s}$, and results reference only non-overlapping components are requested with $50 \mathrm{~m} / \mathrm{s}$.

\subsection{Response and Receiver R2100 Distances}

There are 50 bytes R2100 Distances and echoes data from byte 0 to byte 49 , it may be received data, the first 4 bytes which have $0 \times 01,0 \times$ de, $0 \times 32$ and $0 \times 11$ from byte 0 to byte 3 are used as the sensor starting answers frame, the end byte 49 are used as the end frame number, if a beam does not detect a target, the corresponding R2100 Distance echo values are reported as 0Xffff which means the beam does not detect the target, and it described the echo values as binary number of 111111111111 1111, then, the Advance R2100 values were transferred by programs using for TOMI robot's safety system, R2100 sensors and easy radio response, communicate the Advance R2100 application values which can each other transfer tests data hexadecimal number into decimalize, as the result of thousands data were received and statistic, then, the first author analyzed and gotten the conclusion such as Table 1 and Table 2.

\subsection{Experimental Methods}

R2100 Distance sensors were used and tested in cement space and forage fields where lie on outside of the Precision Agriculture Engineering innovative Centre in UK and in the laboratory of Engineering college, Harper Adams University, such as Figure 3, Considering practical circumstance, five advance R2100 Distance sensors were used on TOMI Robot [10-15]. Before static and dynamic testing, Tests planning need design and write such as testing steps and testing methods, and Static tests were showed as Figure 4: a box, cylinder, cone and person were used as 4 target samples, which were set at various points and lines at $0^{\circ}, 14^{\circ}, 44^{\circ}, 74^{\circ}$ and $88^{\circ}$ angles with the reference of the Advance R2100 sensor at center, and target samples represent as scanning obstacle such as vehicle, telegraph pole, pet and person, respectively.

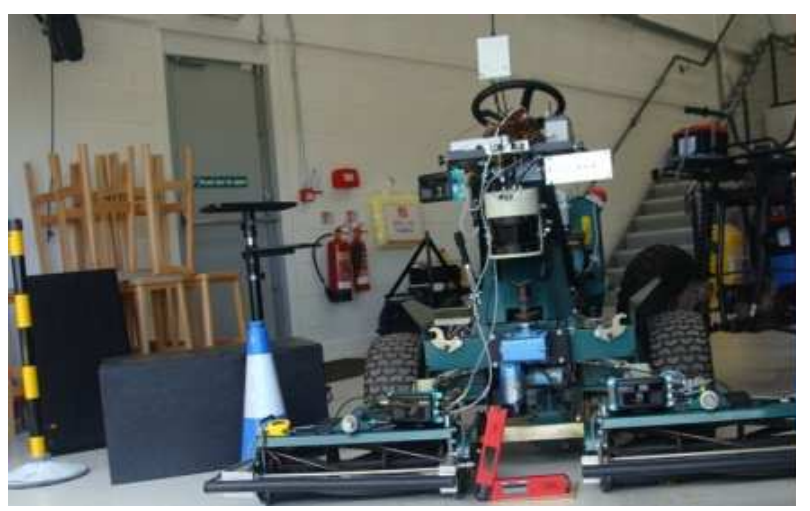

a. Static tests

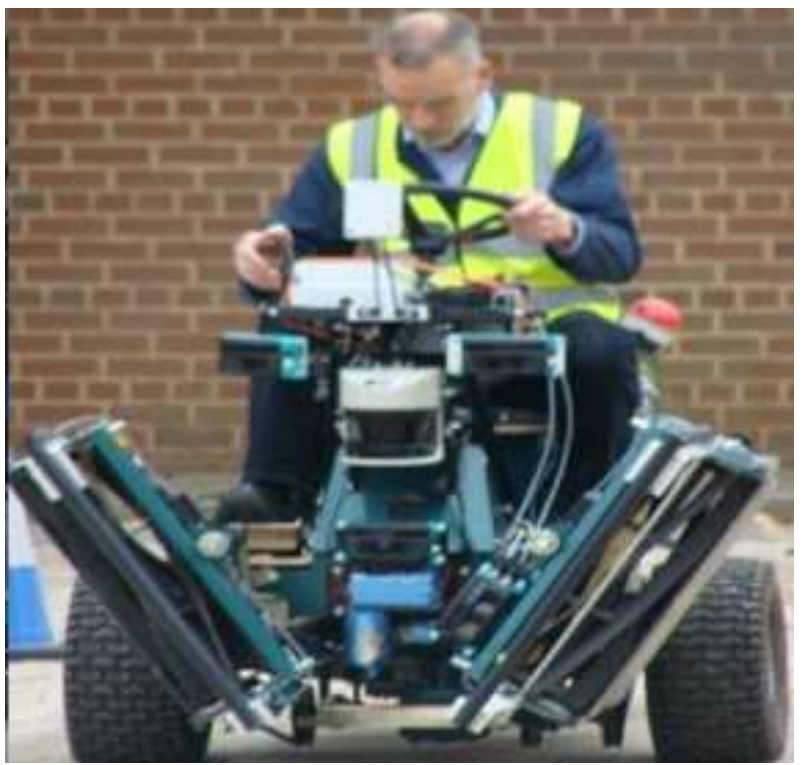

b. Dynamic tests

Figure 3. Photos of statics tests and dynamistic tests of TOMI robot equipped with Advance R2100 sensors.

Advance R2100 Distance sensors were set at 240, 420 and $850 \mathrm{~mm}$ height, respectively, and the 4 targets were classified into static tests and dynamistic tests. Static tests are aimed to detecting the response and received information between 4 target samples and R2100 Distance sensors. Dynamistic tests were aimed to detecting the response and received data about between advance R2100 Distance sensors equipped by TOMI at average velocities $1 \mathrm{~m} / \mathrm{s}$ and other obstacles such as tractors working in fields, and 4 target samples, the different detecting response and received data between dynamistic tests and static tests were carried out, by paralleling $\mathrm{x}-\mathrm{y}$ axis to center axis, the dynamistic vibration amplitude of TOMI equipped with 
advance distance sensor can be received and echo when TOMI was working in fields. Tests results showed that dynamistic tests were more complex and accurate for safety advance R2100 distance sensor using for TOMI robot. The results of dynamistic testing TOMI were affected by the 3D location of R2100, velocities and target samples' angular such as Table 2 and Figure 4.

Table 1. Distances of R2100 sensor in static tests (mm).

\begin{tabular}{lllll}
\hline \multirow{2}{*}{ Target } & Target Size & \multicolumn{3}{l}{ Height of R2100 Distance sensor/mm } \\
\cline { 3 - 5 } & $(\boldsymbol{L} \times \boldsymbol{W} \times \boldsymbol{H}) / \mathbf{m m}$ & $\mathbf{2 4 0}$ & $\mathbf{4 2 0}$ & $\mathbf{8 5 0}$ \\
\hline Cone & $\varnothing 50 \times \varnothing 220 \times 520$ & 10000 & 10000 & 0.00 \\
BOX & $420 \times 420 \times 800$ & 5000 & 5200 & 0.00 \\
Person & $300 \times 150 \times 1650$ & 2800 & 3500 & 4500 \\
Cylinder & $\varnothing 50 \times 950$ & 2100 & 2200 & 0.00 \\
\hline
\end{tabular}

Table 1 showed that setting the R2100 sensor used cutting grass on the height of $420 \mathrm{~mm}$ would be working in fields better than setting on the height of $240 \mathrm{~mm}$ and $850 \mathrm{~mm}$.

\section{Results Analysis}

\subsection{Testing Plan}

Firstly, Testing R2100 Distance sensor's application function: The target was put in the center line at $10 \mathrm{~m}, 8 \mathrm{~m}, 6 \mathrm{~m}$, $5 \mathrm{~m}, 4 \mathrm{~m}, 3 \mathrm{~m}, 2 \mathrm{~m}, 1 \mathrm{~m}, 0.5 \mathrm{~m}, 0.4 \mathrm{~m}, 0.3 \mathrm{~m}$ and $0.2 \mathrm{~m}$ respectively, such as dot marks in Figure 4, than, check the safety system about TOMI robot, if it was not stop, that means the R2100 distance sensor did not detect the obstacles; If TOMI immediately stop, that means the R2100 had detected obstacles; continue to check the second segment and get detail information. Secondly, check the left and right of R2100 sensors following the tests plan: such as Figure 2, Figure 3 and Figure 4, static and dynamic tests steps: put the several targets from $0.2 \mathrm{~m}$ to $10 \mathrm{~m}$ in static tests and the angle is $0^{\circ}, 14^{\circ}, 44^{\circ}$, $74^{\circ}$ and $88^{\circ}$ with the horizontal line,

If TOMI robot does not stop in dynamic tests, the target can put TOMI Robot's front at $10 \mathrm{~m}, 9 \mathrm{~m}, 8 \mathrm{~m}, 7 \mathrm{~m} \ldots \ldots 2 \mathrm{~m}, 1 \mathrm{~m}, 0.5$, $0.3 \mathrm{~m}$ and $0.2 \mathrm{~m}$ in working platform, than scanning and checking that; if TOMI robot is stop, that means the advance R2100 Distance sensor echoes and receives data, then, continue to check the other TOMI's R2100 sensor using the similar method; Third, check the segments of R2100, Target was put at one side of TOMI Robot's front at $10 \mathrm{~m}, \ldots \ldots 4 \mathrm{~m}, 3$ $\mathrm{m}, 2 \mathrm{~m}, 1 \mathrm{~m}, 0.5 \mathrm{~m}, 0.3 \mathrm{~m}$ and $0.2 \mathrm{~m}$ as following Figure 4 , if TOMI equipped with the advance R 2100 sensor is not stop, than, the target can go ahead setting at equivalent distant points and lines with divided by each segment at $8^{\circ}$ angle within 11 segments and checking that, if TOMI robot is stop, that means the target's distance has accurately echo, receive the data and the target continue can set at 5, 4, 3, 1 segments to right front R2100 Distance sensor, respectively, than continue to check that with the similar method; If TOMI is immediately stop, that means the target is located at the 7, 8, 9, 11 segments. Lastly, more detailed information about the two front R2100 Distance sensors can be set, and which segment is linked with the target, following Figure 3 and Figure 4, it was divided $88^{\circ}$ into 11 parts with 12 lines and 11 segments which each segment is about $8^{\circ}$, then, following the above steps and checks the other R2100 Distance sensors.

In the dynamistic tests, the practical fields of working conditions were imitated [12] and TOMI robot was run at 1 $\mathrm{m} / \mathrm{s}$ up to the center of semicircle map, then, following the static tests plan and test diagram to continue the dynamistic tests, the results of tests was shown in the Table 1, Table 2 and Figure 4.

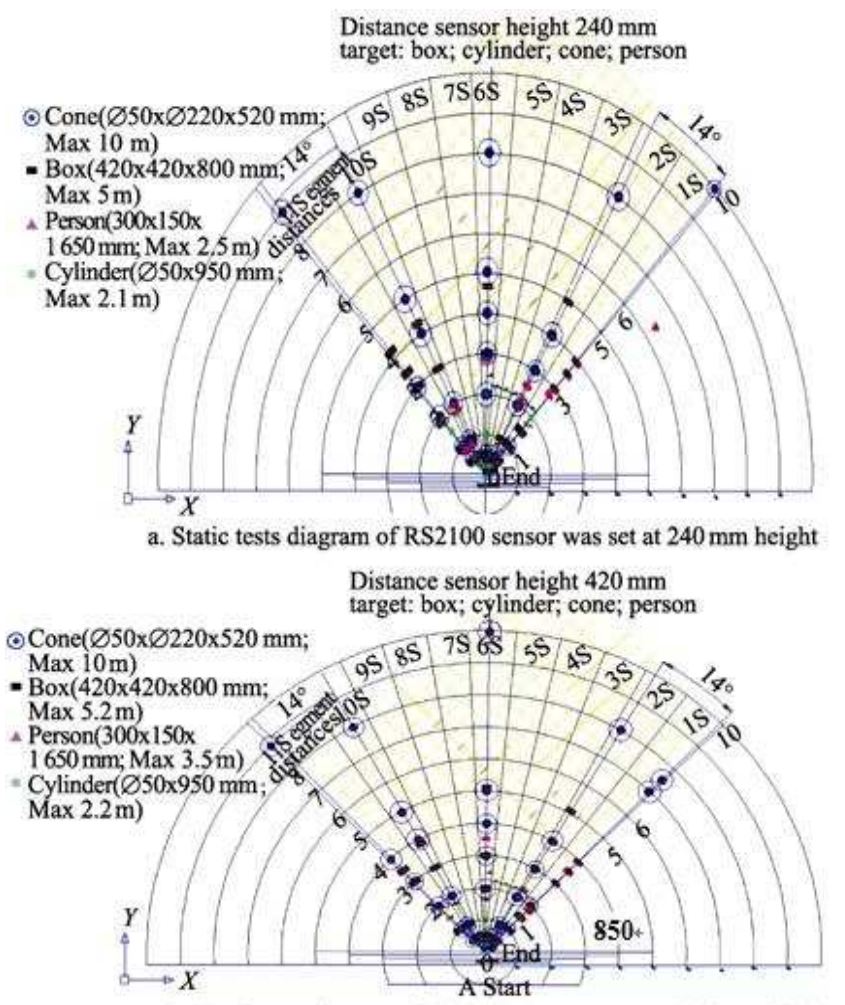

b. Static tests diagram of $R 2100$ sensor was set at $420 \mathrm{~mm}$ height

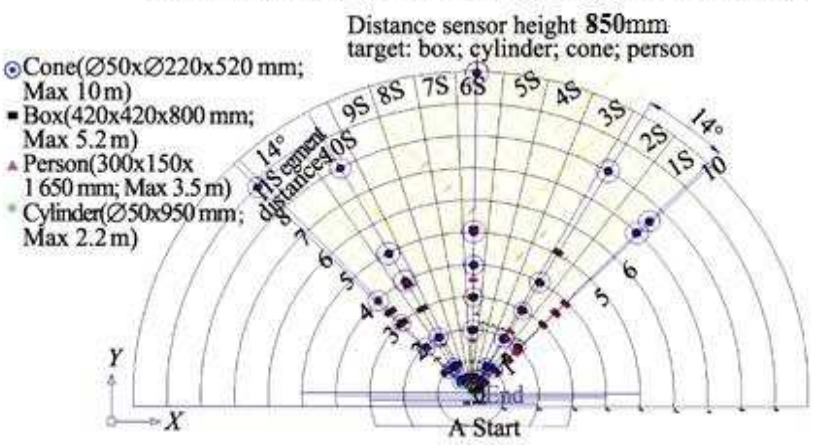

Figure 4. Responded and received dots data in Static tests diagram of $R 2100$ sensor was set at the height of $240 \mathrm{~mm}, 420 \mathrm{~mm}$ and $850 \mathrm{~mm}$, respectively (1 10 means equal to from $1 \mathrm{~m}$ to $10 \mathrm{~m} ; 1 \mathrm{~S} \sim 11 \mathrm{~S}$ means Advance 2100 distance sensor's segments)

\subsection{Test Results and Evaluate}

TOMI robot's static tests were carried out by setting at 240 $\mathrm{mm}, 420 \mathrm{~mm}$ and $850 \mathrm{~mm}$ height, and the target samples were set at $0.2 \mathrm{~m}, 0.3 \mathrm{~m}, 0.5 \mathrm{~m}, 1 \mathrm{~m}, 1.5 \mathrm{~m}, 2 \mathrm{~m}, 2.5 \mathrm{~m}$ and then with added up to $0.5 \mathrm{~m}$ step up to $10 \mathrm{~m}$ with the reference of the 
sensor of semicircle center, respectively. In dynamistic testing, the target samples were set by the same methods and location with static tests, while, TOMI Robot equipped with R2100 Distance sensors worked at constantly speed average $1 \mathrm{~m} / \mathrm{s}$ running which fluctuating from $0.8 \mathrm{~m} / \mathrm{s}$ to $1.2 \mathrm{~m} / \mathrm{s}$ velocities rates, the advance R2100 Distance is far from $5 \mathrm{~m}$ to the test center. Static test and dynamistic test results were shown in Table 1 and Table 2.

Table 1 showed the result of static tests with maximum R2100 Distances of TOMI robot and 4 kinds of targets were set static situation for testing. Table 2 were the result of dynamistic test which TOMI robot working at constantly average speed of $1 \mathrm{~m} / \mathrm{s}$, thousands of data were selected to check the R2100 sensor's sensitively, accuracy and detection range, Table 2 implied that the result of limited data can get valuable evaluation, which these regressions must be suited to the curvilinear character of the relationships, because of Advance R2100 Distance sensor's dynamistic tests based on complex circumstance from on 28, SEP, 2014 to on 4, OCT, 2014, the data of testing showed that the value of OMD8000-R2100-R2-2V15 advance type R2100 Distance sensor was nearly equal to designer's purpose of industrial products [13-21], but the accuracy tolerance of dynamistic tests were not better than that of static tests, dynamistic test's targets were one box, one cylinder, one cone and the first author, the velocity of TOMI is range from 0.8 to $1.2 \mathrm{~m} / \mathrm{s}$ and average velocity was $1 \mathrm{~m} / \mathrm{s}$.

From Table 1 to Table 2, static tests and dynamistic tests were carried out, the best height and application distance of R2100 sensor were gotten from the static and dynamistic testing, From Table 1, the R2100 Distance sensor setting on the height of $850 \mathrm{~mm}$ can scan person target up to $8425.50 \mathrm{~mm}$ maximum distance, but box, cylinder and cone targets may scan nothing at this height.

From Figure 1 to Figure 6 and Table 1, Table 2, It can be seen that the accurate results of adaptable scanning distances ranges which between 4 serious of obstacles targets and advance R2100 distance Sensor in static tests and dynamic tests, which operating methods were complied with ISO standards of Agricultural machine's safety operational systems [22-27], it was shown in Figure 5, the box, cone, cylinder and the first author targets were set at $0^{\circ}, 14^{\circ}, 44^{\circ}, 74^{\circ}$ and $88^{\circ}$ angle with the reference of the R2100 sensor at center, and every 5 regression equations showed the relationships between the target's actual R2100 Distances value and the theory value of R2100 sensor at the height of $240,420 \mathrm{~mm}$, respectively. the accuracy tolerate and suitable height also were evaluate of person target at 240, 420, $850 \mathrm{~mm}$ height in Figure 5 and Figure 6, the results from Test 1, Test 3 and Test 5 showed that the average R2 is up to $98.96 \%$, when R2100 sensor was setting at the height of $420 \mathrm{~mm}$ in TOMI robot working in complex fields, it showed that the R2100 sensor setting on $420 \mathrm{~mm}$ height is more accurate scanning person than 240 and $850 \mathrm{~mm}$ height.

Results of Table 2 showed that the advance R 2100 sensor is reliable and accurate, the average $\mathrm{R}^{2}$ of the $\mathrm{R} 2100$ sensor setting at $240 \mathrm{~mm}$ height is up to $99.12 \%$, at $420 \mathrm{~mm}$ height is up to $98.96 \%$, at 3 height level, it can detect the person target when setting at $850 \mathrm{~mm}$ height, it is scanning the max R2100 Distance up to $4500 \mathrm{~mm}$ such as Table 1. Above all, several obstacles would be met by TOMI in various fields, and as far as TOMI new safety systems, it was set at $420 \mathrm{~mm}$ height that would be best location for scanning all kinds of obstacles.

\section{Conclusion and Perspective}

From Table 1, Table 2, and Test 1-9, Static tests, Dynamic tests and statistical analysis results with regression equation which the accuracy tolerate and suitable height were analysised, respectively, are showed that: 1) The advance R2100 Distance sensor can be up to the designer's application function, but the accuracy tolerance of dynamistic tests were not better than the results of static tests, the average $\mathrm{R}^{2}$ is up to $98.96 \%$ in static tests, while the average $\mathrm{R}^{2}$ is up to $98.67 \%$ in dynamistic test; when the Advance R2100 sensor setting at the height of $420 \mathrm{~mm}$ would be the best location for scanning all kinds of obstacles and receive the accurate data such as TOMI robot working in fields.

2) In order to analysis the advance R2100 Distance sensor's function, TOMI equipped with R2100 sensors working in the cement space and forage fields were tested, the dynamistic test showed the similar results with the four targets samples; as far as TOMI robot 's safety systems; the average $\mathrm{R}^{2}$ of $\mathrm{R} 2100$ Distance sensor setting at $240 \mathrm{~mm}$ height is up to $99.12 \%$, at 3 height level, it can detect person target when setting at 850 $\mathrm{mm}$ height, it is scanning the range of distance up to from $4497.00 \mathrm{~mm}$ to $8425.50 \mathrm{~mm}$.

Table 2. Dynamic tests results of R2100 Distance sensor ( $\mathrm{mm})$.

\begin{tabular}{|c|c|c|c|c|c|c|c|c|c|c|c|c|c|c|}
\hline $\begin{array}{l}\text { Sensor } \\
\text { height } / \mathbf{m m}\end{array}$ & Target & Angle/( $\left.{ }^{\circ}\right)$ & $\begin{array}{l}\text { R2100 Distance } \\
\text { value/mm }\end{array}$ & 1 & 2 & 3 & 4 & 5 & 6 & 7 & 8 & 9 & 10 & 11 \\
\hline \multirow{9}{*}{240} & \multirow{9}{*}{ box } & 0 & 8000 & - & - & - & - & - & - & - & - & - & - & 8129.67 \\
\hline & & 0 & 5000 & 4539.13 & 5044.00 & 5044.00 & - & - & - & - & - & - & - & - \\
\hline & & 0 & 3200 & 2991.25 & - & - & - & - & - & - & - & - & - & - \\
\hline & & 0 & 3000 & 2991.25 & - & - & - & - & - & - & - & - & - & - \\
\hline & & 0 & 2000 & 2130.00 & 2192.00 & - & - & - & - & - & - & - & - & - \\
\hline & & 0 & 1300 & 1143.00 & 1097.33 & 1137.71 & 1394.78 & - & - & - & - & - & - & - \\
\hline & & 0 & 1200 & 1153.00 & 1281.00 & 1288.00 & 1337.00 & - & - & - & - & - & - & - \\
\hline & & 0 & 1000 & 1056.19 & 1118.42 & 1039.24 & - & - & - & - & - & - & - & - \\
\hline & & 14 & 1000 & 1153.00 & 1281.00 & 1288.00 & 1337.00 & - & & - & - & - & - & - \\
\hline
\end{tabular}




\begin{tabular}{|c|c|c|c|c|c|c|c|c|c|c|c|c|c|c|}
\hline $\begin{array}{l}\text { Sensor } \\
\text { height } / \mathrm{mm} \\
\end{array}$ & Target & Angle/( $\left.{ }^{\circ}\right)$ & $\begin{array}{l}\text { R2100 Distance } \\
\text { value/mm }\end{array}$ & 1 & 2 & 3 & 4 & 5 & 6 & 7 & 8 & 9 & 10 & 11 \\
\hline \multirow{4}{*}{240} & \multirow{4}{*}{ cone } & 0 & 9000 & 9192.00 & - & - & - & - & - & - & - & - & - & - \\
\hline & & 14 & 9000 & - & 9682.33 & - & - & - & - & - & - & - & - & - \\
\hline & & 74 & 9000 & - & - & - & - & - & - & - & - & 9912.67 & - & - \\
\hline & & 88 & 5000 & - & - & - & - & - & - & - & - & - & 5560.00 & 5461.00 \\
\hline \multirow{2}{*}{420} & \multirow{2}{*}{ cone } & 0 & 8000 & - & 9096.00 & - & - & - & - & - & - & - & - & - \\
\hline & & 88 & 9000 & - & - & - & - & - & - & - & - & - & - & 9528.50 \\
\hline \multirow{8}{*}{850} & \multirow{5}{*}{ cone } & 0 & 10000 & - & 10424.00 & - & - & - & - & - & - & - & - & - \\
\hline & & 0 & 8000 & - & 8618.00 & - & - & - & - & - & - & - & - & - \\
\hline & & 0 & 4500 & - & 5636.00 & - & - & - & - & - & - & - & - & - \\
\hline & & 0 & 3000 & - & - & 4024.00 & - & - & - & - & - & - & - & - \\
\hline & & 0 & 1000 & 1211.00 & 1259.00 & - & - & - & - & - & - & - & - & - \\
\hline & \multirow{3}{*}{ cone } & 44 & 6000 & - & - & - & - & - & 6666.00 & - & - & - & - & - \\
\hline & & 44 & 4000 & - & - & - & - & - & 4734.00 & - & - & - & - & - \\
\hline & & 44 & 4000 & - & - & - & - & - & 4497.00 & - & - & - & - & - \\
\hline
\end{tabular}

Note:"-" means scanning nothing.
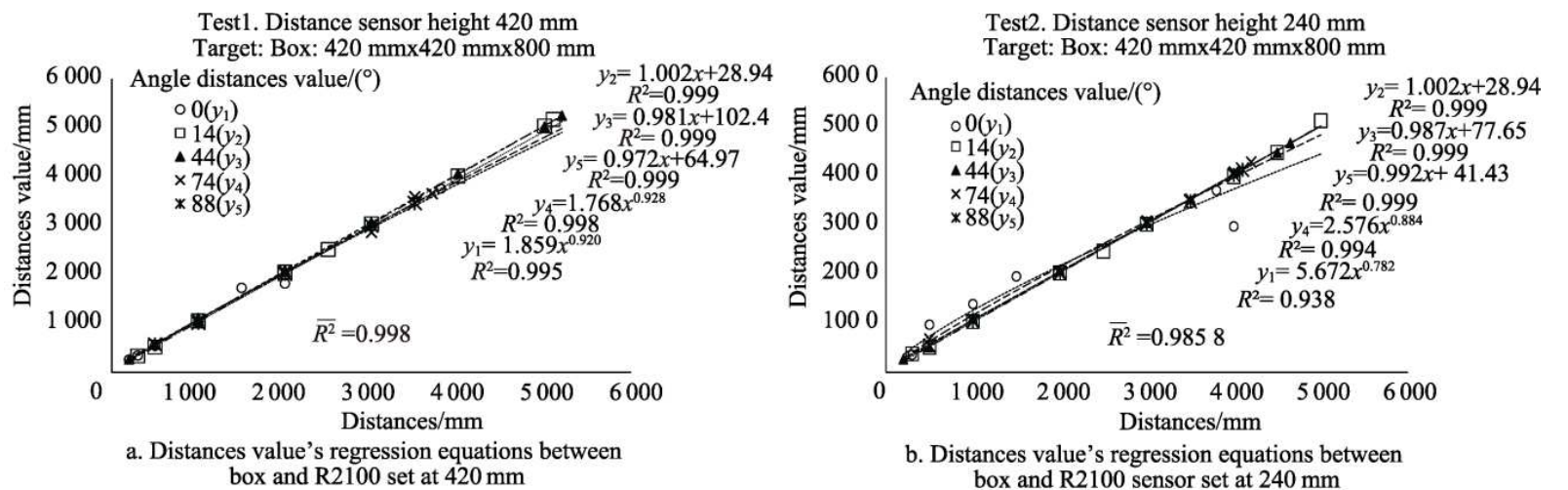
and R2100 set at $420 \mathrm{~mm}$

b. Distances value's regression equations between box and R2100 sensor set at $240 \mathrm{~mm}$

Test3. Distance sensor height $420 \mathrm{~mm}$

Target: Cone: $\varnothing 50 \mathrm{mmx} \varnothing 220 \mathrm{mmxhigh} 520 \mathrm{~mm}$

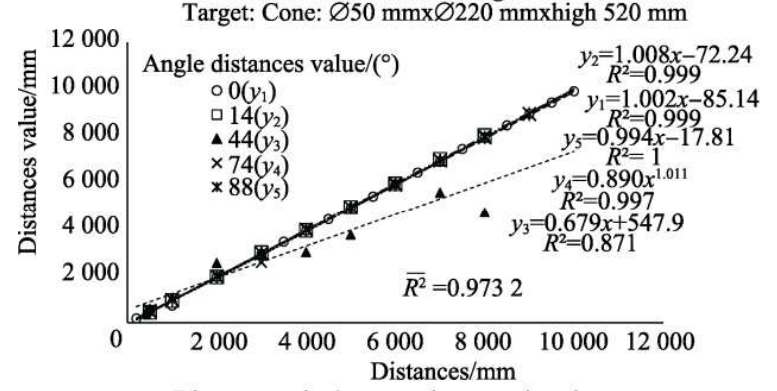

c. Distances value's regression equations between cone and R2 100 sensor set at $420 \mathrm{~mm}$

Test5. Distance sensor height $420 \mathrm{~mm}$

Target: Cylinder: $\varnothing 50 \mathrm{mmx} 950 \mathrm{~mm}$ half diameter

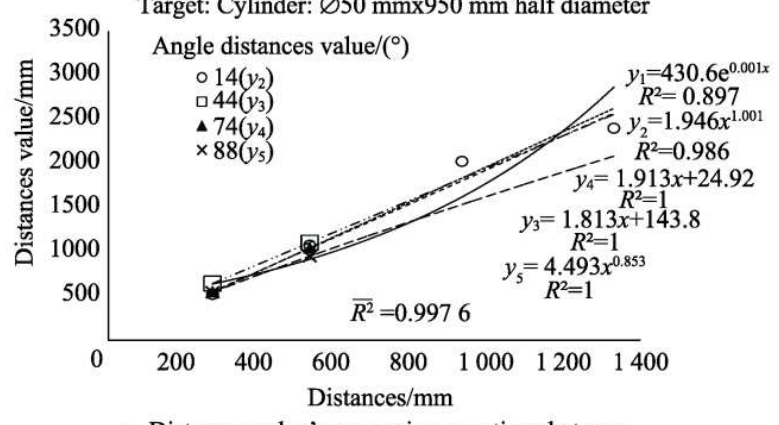

e. Distances value's regression equations between cylinder and R2100 set at $420 \mathrm{~mm}$
Test4. Distance sensor height $240 \mathrm{~mm}$ Target: Cone: $\varnothing 50 \mathrm{mmx} \varnothing 220 \mathrm{mmxhigh} 520 \mathrm{~mm}$

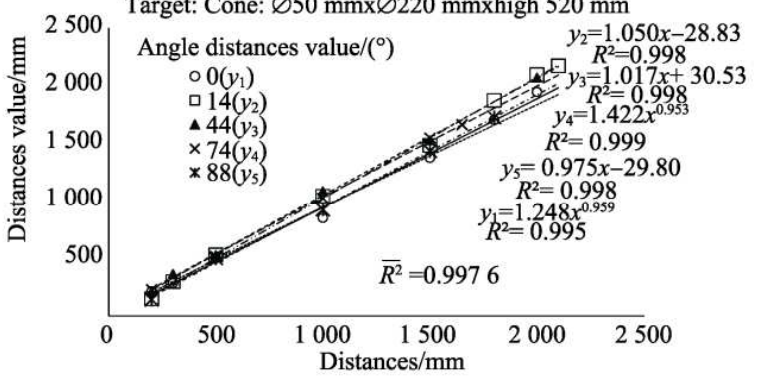

d. Distances value's regression equations between cone and R2100 sensor set at $240 \mathrm{~mm}$

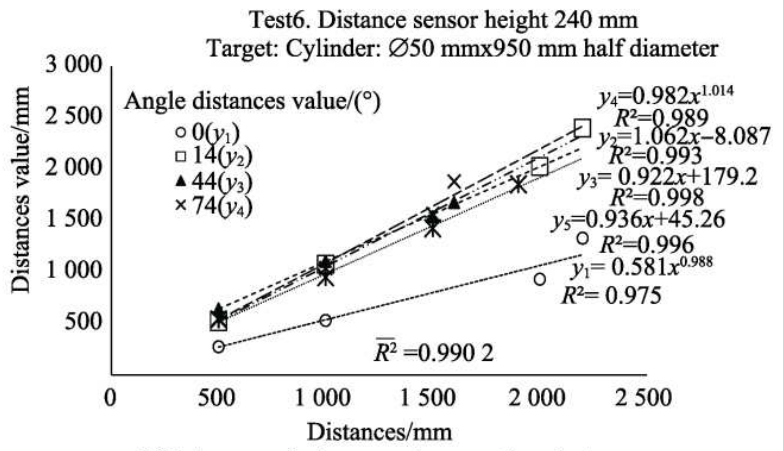

f. Distances value's regression equations between cylinder and R2100 sensor set at $240 \mathrm{~mm}$

Figure 5. Relationship between a box, cylinder, cone, person targets and R2100 sensors in static tests. 

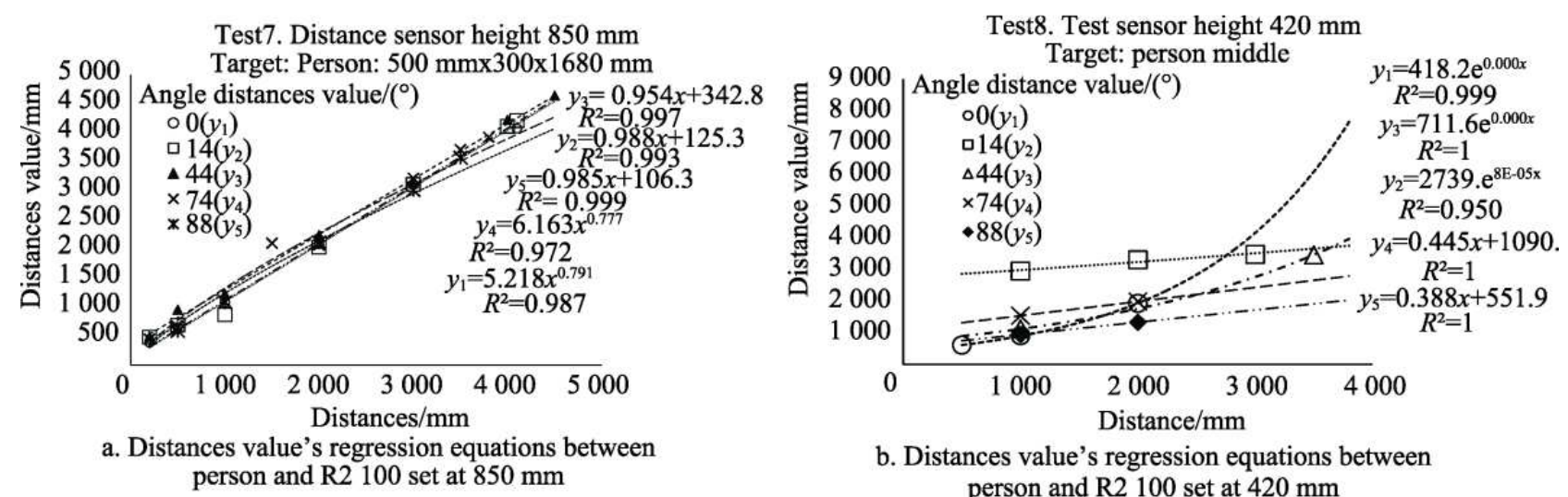

b. Distances value's regression equations between person and R2 100 set at $420 \mathrm{~mm}$

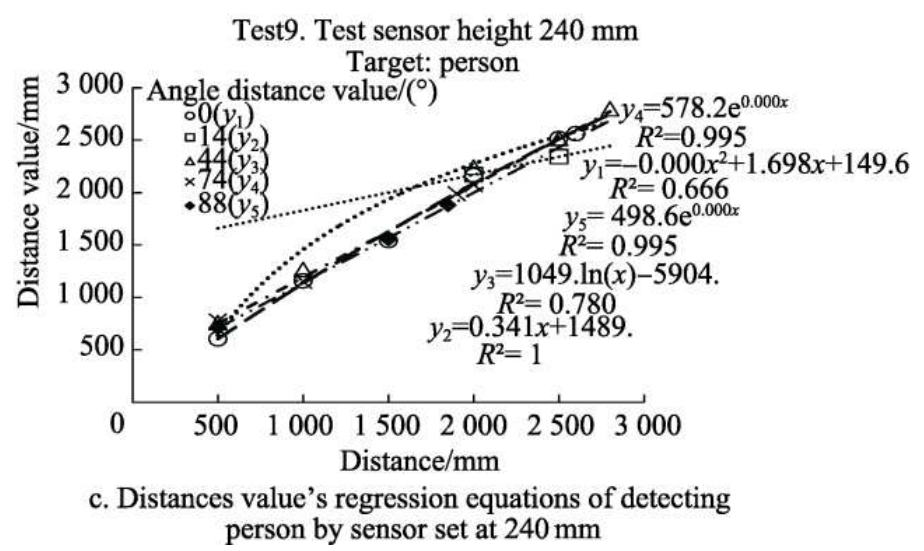

Figure 6. Relationship between person as target and Advance R2100 sensor in dynamic tests.

3) Above all, the results showed that the Advance R2100 sensor is accurate and reliability for detecting various target obstacles in fields. Evaluation the Advance R2100 distance sensor's object were carried out, scanning object tasks were designed according to the spot, shape and size of detectable objects. If target sample is not standard size, the greater tolerance would be obtained such as Table 2. If a smaller object is to be detected, the inductive proximity sensor requires detecting the Advance R2100 Distance in the specification situation. Researching harvester equipped with Advance R2100 Distance sensors are suggested to detect and echo the best location for scanning and echo obstacles.

\section{Acknowledgements}

ZHAO CHUNHUA would like to thanks for Professor Simon Blackmore and all of staffs in Engineering College at Harper Adams University, C.H also thanks Y.X for transferred thousands testing hexadecimal Data numbers into decimalize and Statistic them; the research had been carried out at national precision Agriculture Engineering innovative Centre in UK. The paper would be funded by Research and Development of main Project in Gansu Province; National Natural Science Foundation of China; Special Fund for Agro-scientific Research in Public Interest and FXRC outstanding talent project in Gansu province.

\section{References}

[1] Chunhua Zhao, Material Analysis Structural Study on powering Divider of Herbage Harvester [J]. Environmental Science Material Application, 2012, 148-151.

[2] Products introduce, Bumper-datasheet, on Apr, 2014.

[3] E. J. Van Henten D. Goense C. Lokhorst. Precision agriculture rest Wageningen Academic Publishers. Papers presented at the 7th European Conference on Precision Agriculture [C], the Netherlands 6-8 July, 2009.

[4] Starks P J, Zhao D, Phillips W A, et al. Development of canopy reflectance algorithms for real-time prediction of Bermuda grass pasture biomass and nutritive values [J]. Crop Science, 2006, 46 (2): 927-934.

[5] Zhou Zhiyan, Zang Ying, Luo Xiwen, et al. Technology innovation development strategy on agricultural aviation industry for plant protection in China [J]. Transactions of the Chinese Society of Agricultural Engineering, 2013, 29 (24): 1-10.

[6] An Xiaofei, Fu Xinglan, Meng Zhijun, et al. Grain yield data transformation model based on photoelectric principle and its validation [J]. Transactions of the Chinese Society of Agricultural Engineering, 2017, 33 (Supp. 1): 36-41.

[7] Omron Electronics LLC, Safety Product Marketing Manager, Your Inductive Proximity Sensor Strategy: The Technology, Specification, and Implementation of Authored by Reno Sufi [EB/OL], 2013-12-02 http://www.measurements.com.
[2014-01-12]. 
[8] Ma Y. L, Liu D. X, Robots; Flexible Manufacturing Systems and Computer-integrated Manufacturing, Unite 24 and 26 of Special English for Mechanical design and automatic manufacture $[\mathrm{M}]$. Beijing, Chemistry factory publisher, 2006, 7.

[9] Ma Y. L, Liu D. X, Computerized Numerical Control and Numerical Control Applications, Unite 22 and 23 of Special English for Mechanical design and automatic manufacture [M]. Beijing, Chemistry factory publisher, 2006, 7.

[10] www.PEPPERL-FUCHS.com, products introduce, R2100 data sheet, on July, 2014.

[11] Zhou J, Cong B, Liu C. Elimination of vibration noise from an impact-type grain mass flow sensor [J]. Precision Agriculture, 2014, 15 (6): 627-638

[12] Polulu. 2014. R2100 Products of Pepperl+Fuchs AG Ltd. [on-line] Available from: http://www. pololu.com/[Accessed July 2014

[13] Taylorhttp://groups.google.com/group/ieee-tc-agricultural-rob otics, [Accessed Mar, 2014].

[14] Li, Z., Wang, N., Hong, T.. Radio path-loss modeling for a 2.4 $\mathrm{GHz}$ in-field wireless sensor network [J]. Trans. ASABE53 (2), 2010, 615-624.

[15] Mazzetto, F, Calcante, A, Salomoni, F, 2007. A low cost system for the automatic monitoring of slurry distribution activities: the MOSAICO project [C]. In Poster paper proceedings of 6 European Conference of Precision Agriculture (6ECPA), Skiatook, Greece.

[16] Blackmore, B. S. et al., 2004b. Development of a deterministic autonomous tractor. Beijing, CIGR International Conference.

[17] Srivastava. Ajit K., Carroll E. Goering, Roger P. Rohrbach, and Dennis R. Buckmaster. 2006. (rev.) Precision agriculture Chapter 6 in Engineering Principles of Agricultural Machines, 2nd ed., 123-138. St Joseph, Michigan: ASABE, Copyright American Society of Agricultural and Biological Engineers.
[18] Sugahara, K., Nanseki, T., Fukatsu, T. Verification of a prototype system to. In: Proceedings of World Conference on Agricultural Information and IT [C], IAALD AFITA WCCA 2008, Tokyo, Japan, 2008, pp. 215-220.

[19] Van Herten, E. J., Goense, D., Lokhorst, C.: Precision agriculture' 09. In: Papers Presented at the 7th European Conference on Precision Agriculture Wageningen, Wageningen Academic Publishers, The Netherlands, 6-8 July 2009.

[20] Rodrigo, S., Jamisola, Jr., Anthony, A: A path planning strategy for kinematically redundant manipulators anticipating joint failures in the presence of obstacles. In: Proceedings of the 2003 IEEE/RSJ International Conference on Intelligent Robots and Systems as Vegas, Nevada, Oct 2003.

[21] Kang, S. C., Chang, W. T.: Robot Development Using Microsoft ROBOTICS Developer Studio. Taylor \& Francis Group, Boca Raton (2011).

[22] Blackmore, B. S., Fountas, S., Have, H.: System requirements for a small autonomous tractor. CIGR J. Sci. Res. Dev., p. Manuscript PM 04 001, July 2004 (2004a).

[23] R2100-datasheet. https://www.google.co.ukRobotics, D.: 3DR Pixhawk. https://store.3d robotics.com/products/3dr-pixhawk (2014). Accessed 10 Apr, 2014.

[24] Active Robots: 2013. Firgelli. Active Robots Limited. http://www.active-robots.com/brands/firgelli (2014). Accessed 14 May 2014.

[25] Shoji K, Miyamoto M. Improving the accuracy of estimating grain weight by discriminating each grain impact on the yield sensor [J]. Precision Agriculture, 2014, 15 (1): 31-43.

[26] Chung SO, Choi M C, Lee K H, et al. Sensing technologies for grain crop yield monitoring systems: [J]. Journal of Biosystems Engineering, 2016, 41 (4): 408-417.

[27] Robots and robotic devices - Safety requirements for industrial robots-Reference number: ISO 10218-1: 2011 (E). 